\title{
Gender analysis of local budgets in law enforcement and educational organizations of Russia
}

\author{
Aleksei Bogoviz ${ }^{1, *}$, Alexander Averin ${ }^{2}$, and Veronika Yanovskaya ${ }^{3}$ \\ ${ }^{1}$ Federal Research Center of Agrarian Economy and Social Development of Rural Areas - All \\ Russian Research Institute of Agricultural Economics, 123007, Khoroshevskoye shosse, 35k2, \\ Moscow, Russia \\ ${ }^{2}$ Financial University under the Government of the Russian Federation, 125993, Leningradskiy \\ prospect, 49, Moscow, Russia \\ ${ }^{3}$ Plekhanov Russian University of Economics, 115038, Stremyanniy pereulok, 36, Moscow, Russia
}

\begin{abstract}
The authors consider the problem of gender inequality in wages, which exists in Russia and throughout the world. A gendersensitive budget is one way of overcoming gender inequality. The authors study the local budgets of two municipal organizations in the city of Novosibirsk, the local police and the local school, and analyze whether there is gender inequality in wages. They then provide an internal policy on ensuring equal pay for work of equal complexity, which can be used as a guide in state (budgetary) organizations in Russia when drawing up and executing their budgets.
\end{abstract}

\section{Introduction}

The problem of wage differentiation is one of the most researched in economics in particular and within the general domain of social sciences $[1,2]$. Special attention is given to this problem by those specialists studying the problems of labor relations. Despite a large number of scholarly studies on gender inequalities in wages, the statistics analyzed are very imperfect to this day and insufficient to establish strict causal relationships explaining the nature of this phenomenon $[3,4]$. As a rule, gender differences in wages are studied using the methods of econometric analysis of sociological databases [5].

Despite the fact that women have equal rights with men, the problem of gender inequality in wages is quite acute. The explanation of this phenomenon is very important for understanding how the labor market works in Russia. In modern economic relations, the bulk of the economically active population is wage earners for whom wages are the main source of income [6]. It is worth noting that the problem of income gap between men and women is typical not only for Russia but also for many developed and developing countries [7]. May we consider the observed differences the result of discrimination existing against women? Discrimination is an unconditional social injustice and must be eradicated. Consequently, the study of gender wage inequality is such an important topic.

\footnotetext{
* Corresponding author: aleksei.bogoviz@gmail.com
} 
Many countries of the world use social budgeting as an obligatory part of their budgetary processes, because it contributes to the increasing effectiveness and transparency of the budgetary process and makes sure that all the interested social groups are involved and represented, which eventually positively influences the social and economic development of the entire industry, region, and country. Social budgeting is carried out in the interests of various social groups [8]. Gender orientation is the basis of social budgeting. In particular, we are talking about using a gender approach in the budgeting process by highlighting the social component in budgets of different levels and providing resources within a comprehensive policy of equal rights and opportunities.

A gender-oriented budget is the most important tool for overcoming gender inequality. Numerous studies confirm the fact that the eradication of gender inequality positively affects the economic growth and development of human capital [9]. The effectiveness of using budgetary resources is also the result of using a gender approach in budgeting [8]. We can say that the main task of forming and implementing gender budgets is to ensure gender equality in society.

The purpose of this paper is to analyze the budgets of two state (budgetary) organizations and determine whether they have any gender inequality in wages. We consider this problem on the example of two local budgets, the municipal police and the municipal school in the city of Novosibirsk, Russia. Then we propose a scheme for building internal policies designed to ensure equal pay for work of equal complexity, which should be provided in the budgeting of these organizations.

\section{Literature review}

The regression model is used to identify gender (and not only gender, by the way) differences in the wages of wage earners. It allows to decompose the total amount of wages into components and determine the influence of each element of an individual factor independently from the others. As a rule, two models are used. The first model uses the logarithm of the average annual wages. The second model uses the logarithm of the average hourly wage, which is obtained by dividing the monthly wage by the number of hours worked per month [3]. Most often, independent variables are the following: (a) individual characteristics (experience, level of education), (b) the presence of subordinates, (c) the duration of the working day, and (d) the characteristics of the enterprise.

In the literature there are several reasons that explain the nature of gender inequality in the wages of men and women. Employers' preferences are one of the most popular reasons [10]. Very often, female labor is considered by employers as less profitable. Researchers point to the fact that employers see the current benefits and guarantees that are provided to working women, the current labor legislation as an obstacle to achieving high returns on the workforce of women [10]. This stereotype leads to a decrease in the attractiveness of women as wage workers and leads to the so-called "statistical discrimination", which is based on calculating the expected benefits and costs. The different structure of the time budget also supports this stereotype. This trend also leads to the fact that employers invest in the development of women less.

The theory of human capital development asserts that high investments in human capital (education, work experience, acquired skills, etc.) lead to high wages [11]. Thus, the level of wages can be explained by the lower human capital of women. This theory finds confirmation in numerous studies of the labor market in different countries of the world [11]. Another approach, according to the theory of productivity, argues that a woman may be less productive due to the additional amount of family responsibilities, which affect her productivity at work and, accordingly, affects her salary level [12]. 
Thus, there are a large number of approaches to understanding the causes of gender inequality in wages, which interpret the phenomenon according to the influence of various factors.

Analysis of the literature shows that the field of research of gender budgeting in Russia is very poorly studied, which determines the relevance of our study.

\section{Data and methods}

This study conducts a gender analysis of the budgets of two organizations in the city of Novosibirsk. In particular, we have chosen two spheres that are traditionally dominated by the state in Russia, namely, the protection of public order and education. The public order is represented by the municipal police, and the education sector is examined through the school. The composition of workers of these subjects differs in their male/female composition. Another difference is the level of wages.

The municipal police of the Dzerzhinsky district of Novosibirsk includes 60 men and 10 women. The average salary of men in the municipal police was 410,000 rubles per year in 2014 , the wages of women amounted to 280,000 rubles per year. The size of wages of men and women in 2017 amounted to 620,000 rubles and 460,000 rubles, respectively.

Wages make up most of the maintenance of the municipal police (up to $65 \%$ of the budget). It is also possible to consider additional expenses for the police as budget expenditures such as contributions to the Mandatory Health Insurance Fund and the Mandatory Social Insurance Fund, which account for up to 7 percent of the budget expenditure. Other budget items can also be viewed as income of police officers: travel expenses, uniforms, monetary compensation, which all together amount to additional $8 \%$ of the municipal budget's spending.

The staff of the municipal school includes 72 employees, 63 women and 9 men. The average salary of women was 280,000 rubles per year, and it was 310,000 rubles for men in 2014. The amount of wages of men and women in 2017 amounted to 342,000 rubles and 326,000 rubles, respectively. Contributions to the Mandatory Health Insurance Fund and the Mandatory Social Insurance Fund (15\% of the budget for 2017) can also be considered additional sources of income. The main share of budget expenditures $(60 \%)$ was the cost of wages.

We set several tasks in this study. Task 1: compare the wages of men and women in the municipal police of the city of Novosibirsk (Dzerzhinsky district) in 2014 and 2017. Task 2: compare the wages of women and men in education in 2014 and 2017. Task 3: analyze the dynamics of the wage gap existing in these spheres. Task 4: determine the dynamics. Task 5: draw up a scheme of providing policies aimed at ensuring equal pay for work of equal complexity.

\section{Results and discussion}

Using the data given in the previous section, we can solve three research problems and calculate necessary indicators. So, within the first task: (a) the wages of women in police in 2014 is $280,000 / 410000=0.68$, that is $68 \%$ of the wages of men; (b) the wages of women in 2017 is $410000 / 620000=0.66$, that is, $66 \%$ of the wages of men.

The second task: (a) women's wages in the field of education in 2014 is 280,000 / $310000=0.90$, that is, $90 \%$ from the wages of men; (b) the wages of women in 2017 is $326,000 / 342,000=0.95$, that is, $95 \%$ of the wages of men.

Thus, with the increase in wages in the municipal police of the city of Novosibirsk by 2017, the gap between the prosperity of women and men becomes even increased by 2 
percentage points. In education, the gap between men and women, on the contrary, decreased by 5 percentage points. Despite the fact that gender disproportions in wages also exist in education, the gap is much smaller. But it is also worth noting that the general level of remuneration in the municipal educational institution is much lower than that in the municipal police.

On the basis of the reviewed scientific literature, we propose the following scheme for building an internal policy to ensure equal pay for work of equal complexity (see Figure 1). The first step involves considering the titles of job positions and their responsibilities. If any issues do not arise at this stage, the titles of positions coincide with the description of duties, then we can proceed to the second step. In the second step, one compares the wages within each group of jobs. If the difference is less than five percent, then everything is good. However, of the gap is greater, then it is necessary to proceed to the third step. In the third step, one analyzes the reasons for differentiation in wages. If these reasons are biased, then we can talk about discrimination. The fourth stage involves the development of policies that guarantee equal pay for equal work, which involves several cornerstones: (a) introducing the principle of equal pay; (b) drawing up and implementing a wage equalization plan; (c) not creating additional stress in the team; (d) involving employees in policy discussions.

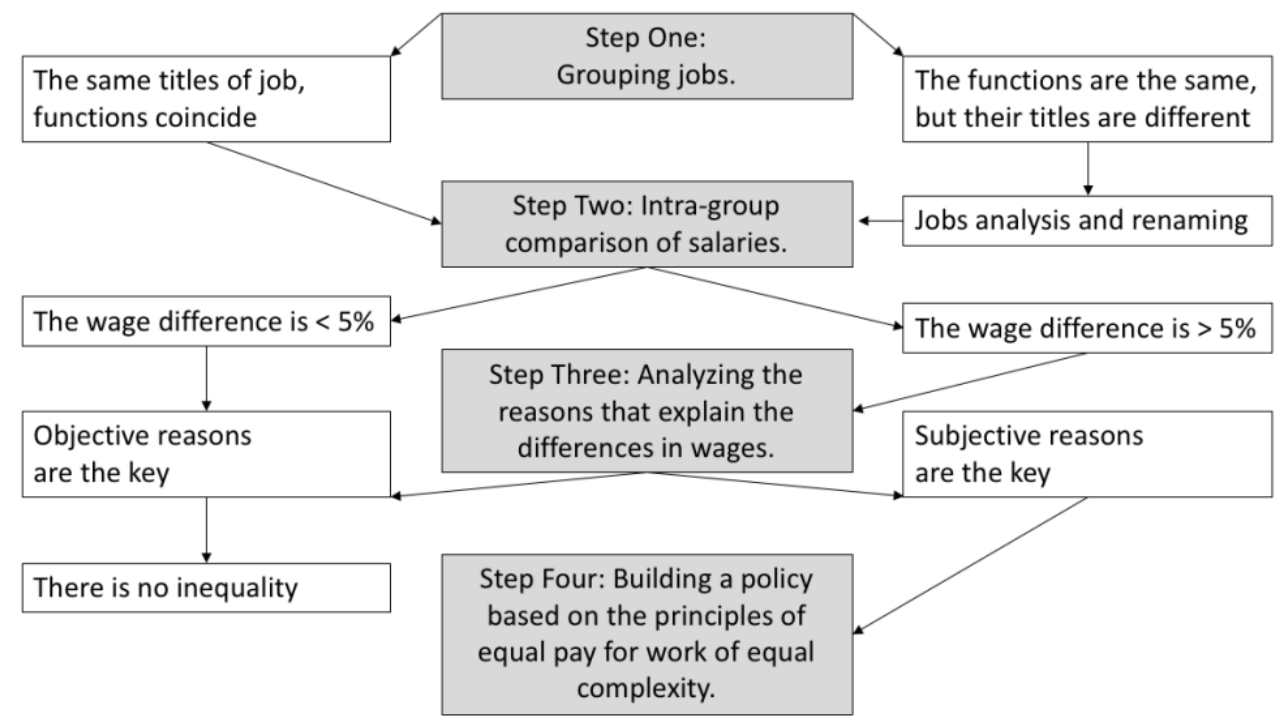

Fig. 1. The scheme for building an internal policy aimed at ensuring equal pay for work of equal complexity.

\section{Conclusion}

Our empirical research on the examples of two state (budgetary) organizations in the sectors of law enforcement and education clearly shows that there are significant differences in wages between female and male workers. On the basis of the scholarly literature studied, we propose a scheme of four steps for building an internal policy aimed at ensuring equal pay for work of equal complexity. This scheme also can be used in social budgeting, strengthening the well-studied gender approach. 


\section{References}

1. P. Bastos, O. R. Straume. Canadian Journal of Economics, 45, 3 (2012)

2. M. Hall, E. Greenman, G. Farkas. Social Forces, 89, 2 (2010)

3. L. Marek, M. Vrabec. International journal of Economics and Statistics, 1, 3 (2013)

4. D. Bilkova. International Journal of Mathematical Research February, 4, 1 (2015)

5. M. Williams. Sociology, 51, 6 (2017)

6. L. Carvalho, A. Rezai. Cambridge Journal of Economics, 40, 2 (2016)

7. A. Oshepkov. HSE Economic Journal, 4 (2006)

8. B. Wampler. Journal of Public Deliberation, 8, 2 (2012)

9. J. U. Elu, L. Loubert.American Economic Review, 103, 3 (2013)

10. D. Bobbitt-Zeher. Gender \& Society, 25, 6 (2011)

11. N. Gennaioli, R. La Porta, F. Lopez-de-Silanes, A. Shleifer. The Quarterly Journal of Economics, 128, 1 (2013)

12. L. Becchetti, S. Castriota, E. C. Tortia. Small Business Economics, 41, 2 (2013) 